\title{
SIR JAMES SIMPSON AND HOSPITAL GROSS-INFEGTION
}

by

\section{S. SELWYN}

Nine TY - Five years after his death James Young Simpson is generally remembered for his pioneer work on anaesthesia. Gynaecologists also celebrate his memory daily by their use of the uterine sound; obstetricians occasionally resurrect such instruments as his obstetric forceps, and may even know of his early work in 'modern' fields such as vacuum extraction. Two other notable and very different facets of Simpson's work are now, however, almost entirely forgotten. His remarkable contributions in medical and general archaeology 1 gained him a European reputation and still repay our attention; whilst his studies on the problems of hospital infection were a preoccupation in his last years, and foreshadow much of our current thought on this subject.

An obituary writer in $1870^{2}$ observed with remarkable insight 'perhaps ... the greatest work in which Sir James engaged was his attempt to diminish the mortality of Surgical Hospitals'. One of the purposes of the present study is to reaffirm this belief from the vantage-point of our own time. In addition, however, it is hoped that attention will be drawn to a branch of medical history whose general neglect has led to much haphazard and repetitious modern work.

The ramifications of Simpson's work on cross-infection are best explored by starting with puerperal fever, then moving by way of 'surgical fever' on to the broader issues of 'Hospitalism'. The fallacy of dividing up the territory with inflexible boundaries was, however, clearly shown by Simpson, and his unified view of the whole is, indeed, one of his major contributions.

Simpson's firm belief in the communicability of puerperal fever originated in observations he made in $183_{3} 6$ at the age of twenty-four, four years before his early appointment to the Edinburgh Chair of Midwifery. Following his participation in the dissection of two fatal cases of puerperal fever, Simpson had in his own practice, for the first time, an outbreak of this disease. It then spread to patients attended by a friend. As a result, from as early as 1840 - three years before the publication of Holmes's celebrated paper on puerperal fever ${ }^{3}$ Simpson lectured on the contagiousness of the disease. ${ }^{4}$ His established views were not, however, published until $1850 ; 5$ and his early experiences were fully described at a meeting of The Edinburgh Medico-Chirurgical Society in $1851 .^{6}$ On that occasion he gave a brilliant exposition of the mode of transmission of puerperal fever, and he also welcomed the recent but neglected work of Semmelweis ${ }^{7}$ as a vindication of his own teachings. He declared that Semmelweis was quite wrong, however, to believe that the disease was transmitted by animal matter in a state of putrefaction. It was evident to Simpson that any putrefaction was incidental and that the disease was spread rather by 'an inflammatory secretion, just as the inoculable matter of smallpox, cowpox, 


\section{S. Selwyn}

syphilis. ... 'Surely for its time a remarkable statement of the specific nature of infection.

It is interesting that during the period when the tragedy of Semmelweis was being enacted, the climate of opinion in Britain was entirely favourable towards these new ideas on puerperal fever. Simpson, who did much to further this cause in Britain, acknowledged his own debt to the curiously neglected work of Alexander Gordon. In I 795 Gordon had published $A$ Treatise on the Epidemic Puerperal Fever of Aberdeen, ${ }^{8}$ which established for the first time the infectious nature of the disease, its transmission by attendants and fomites, and its possible relationships to erysipelas. As a result of this work Gordon, indeed, suffered a fate very similar to that of his successor, Semmelweis. ${ }^{9}$

Developing Gordon's views on erysipelas in relation to puerperal fever, Simpson, in 1851 , described the observations he himself had made fifteen years earlier that 'the same focus of contagion producing puerperal fever in puerperal patients (caused) erysipelas, inflammatory sore throat, \&c., in patients who were not in the puerperal state'. It took a further forty-five years before another Scot, Alexander Ogston, ${ }^{10}$ paved the way for a rigorous proof of Simpson's assertion by dividing the recently discovered micrococci of suppuration into two distinct groups, which he later differentiated by the terms 'staphylococci' and 'streptococci'.

In 1850 , Simpson's paper 'On the analogy between puerperal and surgical fever' 5 had contained a detailed consideration of the clinical features, pathology and epidemiology, showing that both diseases have close similarities, are frequently due to cross-infection and are 'intercommunicable'. His most comprehensive account of surgical fever, however, occurs in the celebrated 'Clinical Lectures' which remained unpublished until 1859. ${ }^{11}$ In these lectures Simpson pointed to the complete neglect of the subject by surgeons, whilst 'every patient placed upon an operating table ... is in . . . greater danger than a soldier entering one of the bloodiest and most fatal battlefields'. Simpson realized that these deaths were not due to 'mortification' of the wound alone but rather 'were engendered by some morbific material circulating in the blood producing a special toxaemic state'. Having observed the transfer of such infections as smallpox between mother and foetus where 'there is no direct vascular communication', he postulated that 'some finer form of morbific agency than pus' was responsible. Applying then his unified view of 'zymotic' diseases he could refute the current opinion that the leucocytosis seen in surgical fever necessarily indicated that pus cells from the wound were the 'morbific agent'. Quite correctly he regarded leucocytosis as a response to infection.

He also described in a striking passage on 'communication by contagious inoculation', the probable mode of transmission of infection by the surgeon, his attendants and nurses, adding, 'I believe that surgical fever is often enough propagated in this way, just as puerperal fever is, ... perhaps . . . to a degree that is at present not yet dreamt of.'

The dangers inherent in the crowded hospitals of his day, too, were dealt with, and proposals for hospital reform were made, foreshadowing his later intensive work in this field. One of his simpler recommendations was that patients 


\section{Sir James Simpson and Hospital Cross-Infection}

should be operated upon soon after their admission to hospital so as to minimize their exposure 'to the vitiated air of an hospital before being subjected to the surgeon's knife'; or, in modern parlance, before they become colonized by pathogenic 'hospital' bacteria. He also suggested that 'in the prophylaxis of surgical fever' fresh wounds could be treated with 'acid, chlorinated or other antiseptic applications'; and this proposal was made at least ten years before Lister's first two papers on the Antiseptic System were published in I867.12, 13 Immediately after Lister's second paper appeared in the Lancet, however, Simpson wrote a scathing reply, pointing out Lister's shortsightedness and lack of originality. ${ }^{14}$

This outburst seemed completely at variance with Simpson's character; and the general view was that he saw Lister's work as a threat to his own cherished principle of 'acupressure', which was gaining support at the time. It did appear likely that this interesting method of haemostasis with needles ${ }^{15}$ would be superseded by ordinary ligatures, made safe under antiseptic cover. Simpson, however, took a much broader view, and saw as a retrograde step Lister's total dependence on his 'new' Antiseptic System. Simpson felt that his neighbour's methods could only impede the wide hospital reforms for which he was striving. Already, in fact, Simpson had begun his great and final battle against 'Hospitalism'.

This word was defined in $\mathrm{I}^{888^{16}}$ as 'Sir James Simpson's term for the totality of the morbific influences which he believed to exist in all large hospitals from the aggregration of sick persons, mostly giving off substances which tend to produce and propagate septic disease. ...'The term first appeared as late as I869 in Simpson's paper 'Our existing system of hospitalism and its effects',17 but the disturbing concept had been occupying his attention for at least twenty-five years.

His correspondence of $1845^{18}$ shows Simpson busily collecting statistics of deaths after amputation in different surgical practices. Some of the first results of his investigation into hospitals were read to the Edinburgh Medico-Chirurgical Society in 1847 and were published in the following year. ${ }^{19}$ They revealed an appalling situation throughout Britain, the overall mortality of 46 per cent at Edinburgh Royal Infirmary being typical.

In a report on the Edinburgh Royal Maternity Hospital in 1848 , Simpson ${ }^{20}$ first published his proposals for hospital reform, including the remark ' $I$ have often stated and taught, that if our present medical, surgical, and obstetric hospitals were changed from being crowded palaces,- -with a layer of sick in each flat,-into villages or cottages, with . . . at most, two patients in each room, a great saving of human life would be effected....' The several 'cottages' in a hospital would ideally be built of expendable material so that if necessary they could be dismantled readily and without any compunction. With his antiquarian leanings, Simpson was possibly influenced here by the military hospital reforms made a century earlier by another Edinburgh professor, Sir John Pringle, ${ }^{21}$ and by Pringle's military successor Brocklesby. ${ }^{22}$

Simpson meanwhile was progressing with his collection of surgical mortality figures. In his 1850 paper on puerperal and surgical fevers, ${ }^{5}$ after showing that 


\section{S. Selwyn}

maternal mortality was highest in towns he added 'a similar difference will ... be found to hold good relatively to the success of amputation and other surgical operation in town and country places'. This view was further elaborated in his 'Clinical Lectures'.11

But his most vigorous statement on hospital cross-infection was made in 1867 , during a Presidential Address to the Social Science Association. ${ }^{23}$ On that occasion the entire problem was dealt with comprehensively for the first time; and Simpson's balanced view is evident throughout. The following passage is typical of the whole:

Although the establishment of hospitals is a necessity ... the bringing together within a confined area of many sick persons is . . . perilous. The risks of contamination of the air and of impregnation of the materials of the building with morbid substances, are so greatly increased, that the greatest care is necessary that hospitals should not become pesthouses, and do more harm than good. There is indeed a continual sacrifice of life from diseases caught in or aggravated by hospitals. The risk . . . is least in the best ventilated hospitals. A great supply of air, by immediately diluting and rapidly carrying away the morbid substances evolved in such quantities from the bodies and excretions of the sick, reduces the risk to its minimum.

The proposal to rebuild Edinburgh Royal Infirmary on a new site was, however, a decisive stimulus for more intensive work; and in 1868 Simpson began his final survey of surgical mortality. Amputations were again chosen because differences in surgical skill were relatively unimportant, and numbers were adequate. The results were embodied in a monumental series of papers, all published within a year of his death.

The first of these ${ }^{17}$ opens with a startling comparison between amputation mortality in the Edinburgh Infirmary about the year $174^{\circ}$ and one hundred and twenty years later. When newly built and still relatively small, the hospital had a mortality of 8 per cent, whereas the current level was over 43 per cent; and the mortality in the Parisian hospitals was as high as 62 per cent-this despite improvements in surgical skill, and the introduction of effective anaesthesia. Simpson then describes his ingenious method of collecting data from nearly four hundred country practitioners throughout Britain. He goes on to present elaborate statistical evidence showing that amputations currently being performed in country practices had the same relatively low mortality as in the Edinburgh Infirmary at its inception. Detailed results of amputations in the major British hospitals are then presented showing an overall mortality of $4^{\mathrm{I}}$ per cent. In the third part of his paper he shows that the mortality in small provincial and cottage hospitals tended to fall midway between the extremes of country practice and large hospital practice. The work is thorough, and shows a mastery of the statistical approach, with a full realization of possible sources of error.

After the publication of the first two parts of this paper, a concerted attack was made on Simpson's work. The main assault came, not surprisingly, from the surgeons, whose chief protagonist was Timothy Holmes. ${ }^{24} \mathrm{He}$ had been co-author in 1863 of an official report on the condition of British hospitals; ${ }^{25}$ and one of its main conclusions was that the outcome of surgical treatment was 
unrelated to hospital size. The actual results presented in the report were, however, themselves inconsistent with this conclusion.

Before the first of Simpson's massive counter-attacks appeared, ${ }^{26}$ he had occasion to defend his work in public. At a stormy meeting of the British Medical Association held that summer in Leeds, Simpson, facing bitter opposition, responded with patience and eloquence. ${ }^{27} \mathrm{He}$ justly observed that carping criticism of his work could in no way alter the appalling state of the larger British hospitals.

His published defence took the form of twenty-one 'Propositions on Hospitalism', issued in seven instalments. ${ }^{26,}{ }^{28}$ Each of Holmes's criticisms is answered in detail, but Simpson accomplished here more than self-vindication. As befitted a former student of Moral Philosophy, 'Humanity' and Mathematics at Edinburgh, his propositions are ingenious and supported by sound argument. Starting with the basic assertion that 'the aggregation of patients regulates in a marked degree the results of operations etc. upon them', he moves on to consider individual facets of the problem. A particularly telling argument is used in relation to forearm amputation which had a mortality, in large hospitals, of about 17 per cent-more than thirty times greater than in country practice. Simpson regarded this relatively minor amputation as a sensitive indicator of surgical sepsis. He argues that surgical shock is minimal in the operation, as compared with amputations of the thigh and leg. Consequently Hospitalism alone accounts for the remarkable excess of hospital deaths.

In these final papers, too, Simpson discusses in remarkable detail many concepts which have become fashionable in recent years. Thus he describes

epidermic scales and minute hairs (and) vegetable fibres ... floating in the air ... these bodies, with bacteria, etc., have latterly been detected abundantly in the atmosphere of hospitals and crowded dwellings ... (and) when they find a proper nidus, lead on by their development to fermentations, putrefaction, suppurations, etc.

And again we read of

... floating organic matters in the surgical wards; and more in them than in the medical wards. The extent to which epithelial and other cells contribute in forming the organic matter ... is shown by the dust collected ... . being found to contain in one experiment 36 per cent, and in another $4^{6}$ per cent. These organic ingredients of the hospital-dust give out an odour of horn when burnt, and a fetid, putrid smell when moistened and allowed to decompose. When lying on the floor of the ward, this organic powder can be readily lifted by the passive draughts of air.

Only recently has our attention been redirected towards microscopic air-borne skin scales and 'fibre nuclei' as vehicles for the spread of pathogenic bacteria. ${ }^{29,30}$

Similarly the modern concept of dangerous dispersal of infection by cases and carriers $^{31,} 32$ is, in fact, anticipated in such lines as

among the increased number of sick (in hospital) there may be one invalid, if not more, whose corporeal exhalations infect and pollute the air of the ward ... the hazard from this cause necessarily increases with the increased number of sick persons in a ward; and consequently also in an hospital under one roof. ... The effects of these and other etiological poisons vary with the susceptibility and state of predisposition of those who are subjected to them. 


\section{S. Selwyyn}

Recently, too, partial success has been obtained in preventing wound sepsis using incomplete pre-operative segregation. ${ }^{33}$ Such results are in accordance with Simpson's dictum 'the more that patients are separated and isolated they recover the more surely from the knife of the surgeon . . . there is safety in segregation-danger in aggregation'. The modern authors cited have undertaken to try the effects of improved ventilation. Simpson would have rejoiced.

The last paper in this series was published after Simpson's death in $1870 .{ }^{28} \mathrm{It}$ deals with suitable modifications to improve the 'insalubrious character' of existing hospitals. Effective isolation of individual wards was to be achieved either by opening up corridors and staircase to the flushing action of fresh air, or by allowing entrance to the wards from external balconies and galleries only. These, with other details of ventilation, would allow 'each ward to become a separate cottage hospital, as it were'. The present Edinburgh Royal Infirmary, built on the cottage or pavilion system shortly after Simpson's death, happily incorporates many of his principles.

Simpson's profound interest in hospital cross-infection continued until the very end of his life. His biographer, Duns, movingly depicts the dying Simpson deeply regretting his inability to complete the work on Hospitalism, and adding 'I hope some good man will take it up'. ${ }^{34}$

After his death there was much discussion about providing a suitable memorial to one who had been a great obstetrician, gynaecologist, pathologist, physician, teacher, epidemiologist, medical politician, public health reformer, religious pamphleteer, archaeologist and philanthropist. The Lancet ${ }^{35}$ was not satisfied that a hospital would be appropriate. The leader writer felt that it must certainly not be 'a lying-in hospital' whose 'evils' had been strongly denounced by Sir James, nor could it be 'a permanent and palatial structure' which would perpetuate 'the very faults from which he most recoiled'.

This notwithstanding, The Simpson Memorial Maternity Hospital came into being. It was later moved to a site adjoining The Royal Infirmary, and stands to this day 'permanent and palatial'.

\section{ACKNOWLEDGEMENT}

I wish to thank Mr. G. R. Pendrill, Librarian to the Royal College of Physicians, Edinburgh, for his help in locating texts.

\section{REFERENCES}

I. Sim Pson, J. Y., Archaeological Essays, 2 vols., ed. J. Stuart, Edinburgh, Edmonston and Douglas, 1872.

2. Obituary, Sir James Y. Simpson, Bart., Brit. med. J., 1870, i, 505-7.

3. Holmes, O. W., The contagiousness of puerperal fever, 1843 , reprinted in Medical Classics, Baltimore, The Williams and Wilkins Co., 1936-7, vol. I, pp. 2 I $1-43$.

4. Simpson, J. Y., On the analogy between puerperal and surgical fever, Edinb. mthly. F. med. Sci., 1850, II, 414-29.

5. - Edinb. mthly. F. med. Sci., II, 414-29.

6. On the communicability and propagation of puerperal fever, Edinb. mthly. 7. med. Sci., 1851, 13, 72-81. 


\section{Sir Fames Simpson and Hospital Cross-Infection}

7. Semmelweıs, I. P., Höchst wichtige Erfahrungen über die Ätiologie der in Gebäranstalten epidemischen Puerperalfieber, Ztschr. d.k.-k. Gesellsch. d. Aerzte zu Wien, 1847,4 , pt. ii, 242-4; 1849, 5, 64-5.

8. Gordon, A., A Treatise on the Epidemic Puerperal Fever of Aberdeen, London, G. G. and J. Robinson, I795.

9. Por te R, I. A., Alexander Gordon, M.D. of Aberdeen, 1752-I799, Edinburgh, Oliver and Boyd, 1958, pp. $5^{\mathrm{I}-4}$.

10. Ogston, A., Report upon micro-organisms in surgical diseases, Brit. med. F., I881, i, 369-75.

I I. Simpson, J. Y., Clinical lectures, Med. Times $\mathcal{E}$ Gaz., 1859, 39, 41 I-I 4, 437-40, 489-91.

12. Liste R, J., On a new method of treating compound fracture, abscess, etc. with observations on the conditions of suppuration, Lancet, 1867, i, 326-9, 357-9, $387-9,507-9$; ii, 95-6.

13. On the antiseptic principle in the practice of surgery, Lancet, 1867, ii, 353-6.

14. Simpson, J. Y., Carbolic acid and its compounds in surgery, Lancet, 1867, ii, $546-9$.

15. Acupressure: a new method of arresting haemorrhage and of accelerating the healing of wounds, Edinburgh, Adam and Charles Black, 1864 .

16. Lexicon of Medical and Allied Sciences, London, The New Sydenham Society, 1888.

17. Sim P s o , J. Y., Our existing system of hospitalism and its effects, Edinb. med. F., $1869,14,816-30,1084-1115 ; 15,523-32$.

18. Duns, J., Memoir of Sir James $\Upsilon$. Simpson, Bart., Edinburgh, Edmonston and Douglas, 1873, pp. $174-7$.

19. Simpson, J. Y., Does anaesthesia increase or decrease the mortality attendant upon surgical operations? Edinb. mthly. 7. med. Sci., 1848, 8, 697-710.

20. - Report of the Edinburgh Royal Maternity Hospital, Edinb. mthly. 7. med. Sci, 1848, 9, 328-33.

21. Pringle, J., Observations on the diseases of the army, in camp and garrison. In three parts, with an Appendix, London, A. Millar, D. Wilson and T. Payne, I752, pp. viii, xii, 102-5, $121-35,290-4$.

22. BROGKLESBY, R., Oeconomical and medical observations, in two parts. From the year $175^{8}$ to the year 1763 , inclusive. Tending to the improvement of military hospitals, and to the cure of camp diseases incident to soldiers (with appendix), London, T. Becket and P. A. De Hondt, I 764, pp. 53-81.

23. Simpson, J. Y., Presidential Address, On public health, Transactions of the National Association for the Promotion of Social Science, 1867, pp. 107-23.

24. Holmes, T., On 'hospitalism', being a criticism on some papers with the above title, by Sir J. Y. Simpson, Lancet, I869, ii, 194-6, 229-30.

25. Bristowe, J. T., and Holmes, T., On the hospitals of the United Kingdom, Sixth Report of the Medical Officer of the Privy Council, London, 1863, pp. 463-743.

26. Simpson, J. Y., Some propositions on hospitalism (in answer to T. Holmes, Esq.), Lancet, I869, ii, 295-7, 332-5, 431-3, 475-8, 535-8, 698-700.

27. EDITORIAL, Lancet, I869, ii, 201-2; Report of thirty-seventh annual meeting of the British Medical Association, Lancet, 1869, ii, 212-14, 252-5.

28. Simpson, J. Y., Some propositions on hospitalism, By the late Sir J. Y. Simpson, Bart., Lancet, I870, ii, 698-700.

29. Davies, R. R., and Noble, W. G., Dispersal of bacteria on desquamated skin, Lancet, 1962, ii, 1295-7.

30. Rubbo, S. D., Pressley, T. A., Stratford, B. G., and Dixson, S., 


\section{S. Selwyn}

Vehicles of transmission of airborne bacteria in hospital wards, Lancet, 1960, ii, $397-400$.

31. HARE, R., and Cooke, E. M., Self-contamination of patients with staphylococcal infections, Brit med. F., I96r, ii, 333-6.

32. Eichenwald, H. F., Kotsevalov, O., and Fasso, L. A., The 'cloudbaby': an example of bacterial-viral interaction, Amer. 7. Dis. Child., 1960, I00, I6I-73.

33. Shooter, R. A., Thom, B. T., Dunkerley, D. R., Taylor, G. W., Parker, M. T., Juhn, M., and Richards, I. D. G., Pre-operative segregation of patients in a surgical ward, Brit. med. $\mathcal{F}$., 1963, ii, $1567-9$.

34. Duns, J., op. cit., pp. 527-8.

35. Editorial, Lancet, 1870, ii, 19-20. 